\title{
Mifepristone-misoprostol combination in medical termination of early pregnancy
}

\section{Devdatt Laxman Pitale*}

Department of Obstetrics and Gynecology, INHS Patanjali, Karwar, Karnataka, India

Received: 01 January 2018

Accepted: 31 January 2018

\section{*Correspondence:}

Dr. Devdatt Laxman Pitale,

E-mail: dipu.pitale@gmail.com

Copyright: (C) the author(s), publisher and licensee Medip Academy. This is an open-access article distributed under the terms of the Creative Commons Attribution Non-Commercial License, which permits unrestricted non-commercial use, distribution, and reproduction in any medium, provided the original work is properly cited.

\begin{abstract}
Background: Unplanned and unwanted pregnancies are common worldwide despite of the medical advancements and wider availability of contraceptive methods. The development of safe, effective, inexpensive, nonsurgical methods of abortion is thus highly desirable. Objective of present study was to evaluate the effectiveness of Mifepristone $200 \mathrm{mg}$ orally followed by Misoprostol $800 \mu \mathrm{g}$ intravaginally 48 hours later in women undergoing medical termination of early pregnancy (up to 63 days of gestational age).

Methods: The present study included 100 pregnant women requesting termination of pregnancy in first trimester attending the department of Obstetrics and Gynecology. Women with gestational age up to 63 days from the first day of the last menstrual period with previous regular cycles were studied. Patients without medical or surgical contraindications to Mifepristone and Misoprostol were included.

Results: Majority of the pregnant women belonged to the age group between 20-30 years. 30\% of these women were nulliparous and $70 \%$ were multiparous. The period of gestation varied from 35-63 days.90\% of the patients had complete abortion and $10 \%$ had incomplete abortion. All the patients expelled the products of conception within 24 hours of prostaglandin administration. The adverse effects reported were nausea reported by $30 \%$, vomiting by 5 $\%$ and diarrhea by $2 \%$ of the cases. None of the patients reported excess bleeding at the time of abortion, hospitalization or blood transfusion. This regimen has the effectiveness of complete abortion rate with few side effects.

Conclusions: The Mifepristone- Misoprostol combination offers an effective, acceptable, out-patient procedure and an alternative to surgical methods of abortion in medical termination of early pregnancy (up to 63 days of gestation).
\end{abstract}

Keywords: Abortion, Mifepristone, Misoprostol

\section{INTRODUCTION}

Unplanned and unwanted pregnancies are common worldwide despite of the medical advancements and wider availability of contraceptive methods. Most women choose medical abortion because of a desire to avoid surgery, perception that medical abortion is safer than surgical abortion and a belief that medical abortion is more natural and private than a surgical procedure. The development of safe, effective, inexpensive, nonsurgical methods of abortion is thus highly desirable. The medical methods of abortion have been proven to be safe and effective when performed according to the guidelines. ${ }^{1}$

The majority of induced abortions are performed in the first trimester. Vacuum aspiration is, when performed by skilled professionals and with proper equipment, considered relatively safe but is not without risks. Medical abortion offers an alternative to surgical methods, and some of the complications related to surgery, such as uterine ruptures and cervical tears, as well as anesthesia related complications can be avoided. 
Under the existing laws medical methods can only be administered by Gynecologists and Registered Medical Practitioners recognized for performing MTPs by the MTP Act of $1971 .^{2}$

\section{METHODS}

The present study included 100 pregnant women requesting termination of pregnancy in first trimester (up to 63 days of gestation) attending the department of Obstetrics and Gynecology at INHS Asvini during November 2016 to January 2017 and June 2017 to November 2017 at INHS Patanjali.

\section{Inclusion criteria}

- Women with gestational age up to 63 days from the first day of the last menstrual period with previous regular cycles.

- Women without medical or surgical contraindications to mifepristone and Misoprostol.

\section{Exclusion criteria}

- Confirmed or suspected ectopic pregnancy or undiagnosed adnexal mass.

- Intrauterine device in place.

- Patients with cardiac, pulmonary diseases, epilepsy, asthma, renal failure.

- Concurrent long-term corticosteroid therapy.

- Hemorrhagic disorders or concurrent anticoagulant therapy.

- Inherited porphyrias.

- Patients on antifungal drugs and antiepileptic drugs.

100 pregnant women who fulfilled the inclusion criteria requesting medical termination of pregnancy were taken up for the study. A complete case record was prepared and detailed history of all the patients was taken. A thorough clinical examination including general, per abdominal and per vaginal examination was done. All these women were subjected to investigations like complete urine examination, hemoglobin estimation $(\mathrm{Hb} \%)$, blood grouping and $\mathrm{Rh}$ typing and random blood sugar were done prior to the administration of the regimen. Transvaginal Ultrasonography was performed to confirm the gestational age. All the patients were informed about the success rate of medical treatment and explained that if it fails they may need surgical intervention. A written consent was taken.

Each patient was given Tab. Mifepristone $200 \mathrm{mg}$ orally on the same day as the hospital visit or within the following two days. The women were allowed to go home half an hour after the mifepristone administration with an instruction to return to the Gynecology ward after 48 hours. Patients were also informed that in some cases abortion might occur at home following mifepristone. After 48 hours Tab Misoprostol 800ug was kept in the posterior fornix of vagina under strict aseptic precautions.
Vitals were monitored half an hourly before and after the insertion of tablet. Patients were discharged 6 hours later on the same day and were advised to report if there was excessive bleeding, fever, foul smelling discharge, vomiting or any other complications were experienced.

All the patients were under the antibiotic cover of Tab Doxycycline $100 \mathrm{mg}$ bid and Tab Tinidazole 500mg bid for 7 days. Patients were instructed to report on the 14th day if no complications occurred in between. Transvaginal Ultrasonography was repeated on 14th day to confirm the completeness of abortion. Success was defined as the complete expulsion of the products of conception without the need for surgical intervention. Women who have not responded to medical treatment within 24 hours of Misoprostol administration, were offered surgical methods to terminate the pregnancy.

\section{RESULTS}

Results were analyzed according to age, parity, gestational age, induction abortion interval, completeness of abortion, need for surgical intervention, failure of procedure and complications.

In the present study youngest patient was 20 years old while the eldest was 35 years old, $90 \%$ belonged to $20-30$ years. In the present study, $20 \%$ were primigravidas, $70 \%$ were second gravida and $10 \%$ were third gravida. Most of the patients were second gravida. Most of the patients (80\%) in the present study were between 35-50 days of gestational age (Table 1).

Table 1: Demographic distribution.

\begin{tabular}{|c|c|c|}
\hline & No. of patients & $\%$ \\
\hline \multicolumn{3}{|l|}{ Age (Years) } \\
\hline $20-30$ & 90 & 90 \\
\hline $31-40$ & 10 & 10 \\
\hline \multicolumn{3}{|l|}{ Gravidity } \\
\hline Primigravida & 30 & 30 \\
\hline Second gravida & 60 & 60 \\
\hline Third gravida & 10 & 10 \\
\hline \multicolumn{3}{|c|}{ Gestational age in days } \\
\hline $35-50$ & 80 & 80 \\
\hline $51-66$ & 20 & 20 \\
\hline
\end{tabular}

\section{Induction-abortion interval}

The average induction abortion interval in this study was 8 hours. $80 \%$ of the patients aborted within 12 hours and all the patients aborted within 24 hours.

\section{Complications}

In the present study, ten patients had retained products of conception on repeat ultra-sonogram, which was managed medically with misoprostol $800 \mathrm{mcg}$ (pervaginal). In the present study complications like 
Nausea, vomiting and diarrhea were observed in about $30 \%, 5 \%$, and $2 \%$ of patients respectively. After the third day of the treatment procedure complications declined progressively and by day 14 reports were rare except for mild bleeding and spotting (Table 2).

Table 2: Completeness of abortion and complications.

\begin{tabular}{|c|c|c|}
\hline & No. of cases & $\%$ \\
\hline \multicolumn{3}{|l|}{ Abortion } \\
\hline Complete & 90 & 90 \\
\hline Incomplete & 10 & 10 \\
\hline \multicolumn{3}{|c|}{ Complications } \\
\hline Nausea & 30 & 30 \\
\hline Vomiting & 5 & 5 \\
\hline Diarrhoea & 2 & 2 \\
\hline
\end{tabular}

\section{DISCUSSION}

Each year about 42 million induced abortions are estimated to be performed worldwide. Of these an estimated 20 million abortions are unsafe with developing nations burdened with $97 \%$. Unsafe abortion is a major cause of mortality among women in India accounting for approximately $15 \%$ of maternal deaths. The Ministry of Health and Family Welfare, Government of India declared the year 2001 as the "Year of Safe Abortions". There has been a constant endeavor to make abortion safer and accessible to women. ${ }^{3}$

Mifepristone is an antiprogestin that blocks most of the progesterone receptors. When a prostaglandin is administered 24 to 48 hours after mifepristone, uterine contractions expel the products of conception and the effectiveness of the combination is greatly enhanced. This medical abortion regimen is highly effective and well accepted. ${ }^{4}$

Misoprostol is an effective abortive agent. ${ }^{5}$ The use of Misoprostol has become increasingly common because it is inexpensive, easily stored at room temperature (36 months validity), effective in causing uterine contractions and has few systemic side effects.

There is enough universal evidence to recognize the effectiveness and safety of combining MifepristoneMisoprostol for inducing abortion up to 63 days as approved for use by the Drug Controller of India. Several studies have evaluated the efficacy of mifepristone and prostaglandin combination in terminating early pregnancy in women with gestational age of 49-63 days. The complete abortion rates with this combination therapy varied from $92.1 \%$ in U.S trials to $95.5 \%$ in French trials. $^{3}$

In the present study, $200 \mathrm{mg}$ of mifepristone orally and $800 \mu \mathrm{g}$ of misoprostol intravaginally was used in women less than 63 days of gestation. Complete abortion occurred in $90 \%$ of cases. The success rate of the present study is also comparable to those done by P.Y S, Devi NA and Sahu RR et al using the same regimen (Table 3).

Table 3: Different studies with different dosage regimen and their outcome.

\begin{tabular}{|c|c|c|c|}
\hline $\begin{array}{l}\text { Study } \\
\text { done }\end{array}$ & $\begin{array}{l}\text { Duration of } \\
\text { pregnancy (no. } \\
\text { of patients) }\end{array}$ & $\begin{array}{l}\text { RU } 486 \text { and PG } \\
\text { dose }\end{array}$ & $\begin{array}{l}\text { Success } \\
\text { rate }\end{array}$ \\
\hline $\begin{array}{l}\text { PYS, } \\
\text { Devi } \\
\text { N.A }\end{array}$ & 73 days (50) & $\begin{array}{l}200 \mathrm{mg}+600 \mu \mathrm{g} \\
\text { misoprostol } \\
\text { vaginally }\end{array}$ & $96 \%$ \\
\hline $\begin{array}{l}\text { Sahu } \\
\text { RR et } \\
\text { al }\end{array}$ & 49 days (40) & $\begin{array}{l}200 \mathrm{mg}+400 \mu \mathrm{g} \\
\text { misoprostol } \\
\text { vaginally and } \\
\text { Sublingually }\end{array}$ & $90 \%$ \\
\hline $\begin{array}{l}\text { Present } \\
\text { study }\end{array}$ & $<63$ days $(100)$ & $\begin{array}{l}200 \mathrm{mg}+800 \mu \mathrm{g} \\
\text { misoprostol } \\
\text { vaginally }\end{array}$ & $90 \%$ \\
\hline
\end{tabular}

The most common adverse effects after the treatment were of gastrointestinal in almost all the studies including the present study. ${ }^{7,8}$ Heavy bleeding was not reported in any of the cases in the present study. None required blood transfusion or hospitalization in the present study.

Similar study done by Veena $S$ in 150 patients with a gestation of less than or equal to 63 days, revealed $92.6 \%$ success rate. There was no major side effect in any of the patients and thus this regimen proves to be an effective alternative to surgical methods of abortion. ${ }^{8-10}$

\section{CONCLUSION}

The Mifepristone- Misoprostol combination offers an effective, acceptable, out-patient procedure and an alternative to surgical methods of abortion in medical termination of early pregnancy (up to 63 days of gestation).

Funding: No funding sources

Conflict of interest: None declared

Ethical approval: The study was approved by the Institutional Ethics Committee

\section{REFERENCES}

1. Nivedita K, Shanthi F. Is it safe to provide abortion pills over the counter? A study on outcome following self-medication with abortion pills. JCDR. 2015 Jan;9(1):QC01.

2. MOHFW. Ensuring access to safe abortion and addressing gender biased sex selection. 2015. Available at http://www.fogsi.org/wpcontent/uploads/2015/12/mtp-guidancehandbook.pdf

3. Vani PY, Devi AN. Efficacy of Mifepristone and Misoprostol combination in termination of early pregnancy. IAIM. 2016;3(12):48-54. 
4. FOGSI focus on Medical abortion. FOGSI-ICOGGCPR guidelines (2011). Available at www.issuu.com/fogsi/does/medical abortion 2011.

5. Faundes A, Fiala C, Tang, Velasco A. Misoprostol for the termination of pregnancy up to 12 completed weeks of pregnancy. Int $\mathbf{J}$ Gynecol Obstet. 2007;99:S172-S177.

6. Sahu RR, Soni AA, Raut VS. Randomised control study on oral vs vaginal and sublingual misoprostol with mifepristone for first -trimester MTP. Indian J Clin Pract. 2013;24(7).

7. Von Hertzen H, Huong NT, Piaggio G, Bayalag M, Cabezas E, Fang AH et al. Misoprostol dose and route after mifepristone for early medical abortion: a randomised controlled noninferiority trial. BJOG. 2010 Sep 1;117(10):1186-96.

8. Veena S. Safety, efficacy and acceptability of medical abortion with mifepristone and misoprostol in Nepalese women. N J Obstet Gynecol. 2007;2(2):54-8.

9. Crenin M, Grossman D. Committee on Practice Bulletins-Gynecology and the Society of Family Planning. 2014;143. Available at https://www.acog.org//media/PracticeBulletins/Committee-on-PracticeBulletins-Gynecology/Public/pb143.pdf

10. FOGSI ICOG Good Clinical Practice Recommendation. J Obstet Gynecol India. 2011:902. Available http://medind.nic.in/jaq/t11/i1/jaqt11i1p90.pdf

Cite this article as: Pitale DL. Mifepristonemisoprostol combination in medical termination of early pregnancy. Int J Reprod Contracept Obstet Gynecol 2018;7:1035-8. 